M. López • L. M. Seoane · S. Tovar • M. C. García •

R. Nogueiras $\cdot$ C. Diéguez $\cdot$ R. M. Señarís

\title{
A possible role of neuropeptide $Y$, agouti-related protein and leptin receptor isoforms in hypothalamic programming by perinatal feeding in the rat
}

Received: 8 June 2004 / Accepted: 5 August 2004 / Published online: 23 December 2004

C) Springer-Verlag 2004

\begin{abstract}
Aim/hypothesis: Perinatal overfeeding predisposes humans and rats to obesity and diabetes in later life. One classical model for studying the effect of early feeding is manipulation of the size of rat litters. Rats growing up in small litters gain more weight than rats growing up in normal-sized litters. Interestingly, these obese rats maintain this phenotype in adulthood. Conversely, rats raised in large litters show a delay in growth and a decrease in body weight. The aim of this work was to assess the hypothalamic control mechanisms of food intake regulated by perinatal feeding. Methods: Leptin levels were analysed using RIA. Leptin receptor mRNA levels were analysed using RT-PCR. Neuropeptide mRNA levels were analysed using in situ hybridisation. Results: Perinatally overfed neonatal male rats exhibited hyperleptinaemia and a decrease in hypothalamic mRNA levels of the long isoform of the leptin receptor (OB-Rb), explaining their leptin resistance. Moreover, this obese model showed an increase in the mRNA expression of cocaine- and amphetamine-regulated transcript, neuropeptide $\mathrm{Y}$ and agouti-related protein in the hypothalamic arcuate nucleus (ARC). In contrast, perinatally underfed neonatal male rats with hypoleptinaemia showed an increase in hypothalamic mRNA of the short isoforms of the leptin receptor. Furthermore, they exhibited an increase in expression of neuropeptide $\mathrm{Y}$ and agoutirelated protein in the ARC. Conclusions/interpretation: Rats overfed during early postnatal life show a leptinresistant state mediated by down-regulation of the hypothalamic OB-Rb. These data, together with the increased expression of neuropeptide $\mathrm{Y}$ and agouti-related protein in specific neurons in the ARC, might indicate
\end{abstract}

M. López · L. M. Seoane · S. Tovar · M. C. García

R. Nogueiras $\cdot$ C. Diéguez $\cdot$ R. M. Señarís $(\bowtie)$

Department of Physiology, School of Medicine, University of

Santiago de Compostela,

Spain

e-mail: fsrsr@usc.es

Tel.: +34-98-1582658

Fax: +34-98-1574145 the existence of regulated programming in this nucleus and may provide a new aetiopathogenic concept in susceptibility to obesity.

Keywords Agouti-related protein · Arcuate nucleus · In situ hybridisation - Leptin receptor - Leptin resistance . Neuropeptide Y · Obesity · Overfeeding · Programming · Underfeeding

Abbreviations AgRP: Agouti-related protein - ARC: Arcuate nucleus of the hypothalamus - CART: Cocaineand amphetamine-regulated transcript $\cdot \mathrm{DMN}$ :

Dorsomedial nucleus of the hypothalamus - HPRT:

Hypoxanthine guanine phosphoribosyltransferase - LHA:

Lateral hypothalamic area - LL: Large litter $\cdot \mathrm{MCH}$ :

Melanin-concentrating hormone $\cdot$ NL: Normal-sized litter · NPY: Neuropeptide Y · OB-R: Leptin receptor (five isoforms: Ra, Rb, Rc, Re and Rf) - Prepro-OX: Preproorexin - PVN: Paraventricular nucleus of the hypothalamus - SL: Small litter - TRH: Thyrotropinreleasing hormone

\section{Introduction}

The regulation of feeding is an homeostatic mechanism in which several coordinate systems are implicated $[1,2]$. Among the different levels of regulation, the hypothalamus plays a major role. Thus, feeding is regulated by hypothalamic neuropeptides that promote (orexigenic) or inhibit (anorexigenic) food intake. Of these, neuropeptide $\mathrm{Y}$ (NPY) in the arcuate nucleus (ARC) and dorsomedial (DMN) nucleus of the hypothalamus, agouti-related protein $(\mathrm{AgRP})$ in the ARC, and melanin-concentrating hormone $(\mathrm{MCH})$ and orexins/hypocretins in the lateral hypothalamus (LHA) have prominent orexigenic actions. Among the anorexigenic signals, thyrotropin-releasing hormone (TRH) in the paraventricular nucleus (PVN) and cocaine and amphetamine-regulated transcript (CART) peptides in the ARC, PVN and LHA, play important roles [3, 4]. 
All these neuropeptides are targets of leptin [3, 4]. This hormone exerts its action through the leptin receptor (OB-R). Five splice variants of this protein (OB-Ra, OB-Rb, OB-Rc, OB-Re and OB-Rf) are present in the rat hypothalamus [4, 5]. The long isoform $(\mathrm{OB}-\mathrm{Rb})$ is the variant implicated in signal transduction $[4,5]$. The other isoforms could act as leptin sequesters and transporters, binding leptin without transduction $[5,6]$.

Obesity and associated metabolic alterations are growing problems in public health $[2,7,8]$. Although a positive energy balance is likely to be a final common pathway for obesity, changes in eating behaviour and genetic susceptibility are factors that have emerged recently [2, 9]. Interestingly, becoming overweight during critical developmental periods of fetal and/or neonatal life has been shown to continue throughout juvenile life into adulthood. Thus, epigenetic environmental factors, like fetal and neonatal nutrition, acting during critical perinatal periods, play a key role in the development of obesity $[10,11]$. The specific biological mechanisms underlying fetal/neonatal programming are largely unknown. It has been suggested that hypothalamic dysfunctions $[12,13]$ and programming of relative leptin concentrations by early diet [14] are mechanisms that link early nutrition with later obesity. Several studies suggest the existence of alterations in the hypothalamic feeding-regulation systems in the postnatal overfeeding model. It has already been shown that these rats are hyperleptinaemic with central leptin resistance [15-18] and hyperinsulinaemic with central insulin resistance $[19,20]$. However, there are no data about the mechanisms underlying this programmed leptin resistance and the possible changes induced by early nutrition on the expression of hypothalamic neuropeptides.

The aim of this study was to assess how perinatal over- and underfeeding, caused by manipulation of litter size, regulates hypothalamic food intake control mechanisms. Thus, we assessed the nuclei-specific expression of different neuropeptides using in situ hybridisation. Furthermore, since leptin resistance is one of the main features of many experimental models of obesity, as well as of human obesity [21], we assessed the expression of the different OB-R isoforms in the hypothalamus.

\section{Materials and methods}

Animals Pregnant female Sprague-Dawley rats (300-350 g) (Animalario General USC, Spain) were housed at $23^{\circ} \mathrm{C}$ under a 12-h light (08.00-20.00 hours), 12-h dark cycle. Animals were allowed free access to standard laboratory pellets of rat chow and tap water. On day 2 of life, newborns were randomly distributed among the mothers. To induce early postnatal over-, under- or normal feeding, the litter size was adjusted on day 2 of life to four to five rats in each litter (small litters, SL, $n=50$ pregnant mothers, early postnatal overfeeding), 22 to 24 rats in each litter (large litters, LL, $n=9$ pregnant mothers, early postnatal underfeeding), or 12 newborns in each litter (normal litters, NL [control], $n=25$ pregnant mothers, normal feeding) $[19,22]$. The number of animals of each sex in the three kinds of litter was balanced. No mortality was found in the NL and SL groups, but in contrast with previous reports [19] mortality in the LL groups was 20 $\pm 4.6 \%$ before day 11; after this time no mortality was detected in that group. Animals were separated from their mothers at day 24 (not at day 21 as in previous reports $[19,22])$ in order to ensure complete weaning [23] due to the known delay to weaning observed in LL pups [19, 22].

The Ethics Committee of the University of Santiago de Compostela approved the protocols, and experiments were performed in agreement with the rules of laboratory animal care and international law on animal experimentation.

Body measurements and sample collection Animals were weighed twice per week. On day 24, the length of the rats was measured (excluding tail: nasal-anal distance) and the relative body weight/body length $(\mathrm{g} / \mathrm{cm})$ was determined. On this day, 16 to 20 male rats from each group were randomly assigned to the investigation presented here. The growth curves presented in Fig. 1 correspond to male rats; female rats showed a similar pattern of growth.

Rats were quickly decapitated, in a separate room, and their brains removed. One set of brains (6-10 animals per experimental group) was removed intact for in situ hybridisation analysis. In the other set of brains (10 animals per
Fig. 1 a Evolution of body weight during the suckling period of male rats from normalsized litters $(N L)$, small litters $(S L)$ and large litters $(L L)$. The arrow shows the time of the adjustment of litter size (day 2). $* * p<0.01$ vs. NL; ${ }^{* * *} p<0.001$ vs. NL. In order to simplify the figure, comparisons between SL and LL groups have been omitted. b NL, SL and LL male rats at 24 days old

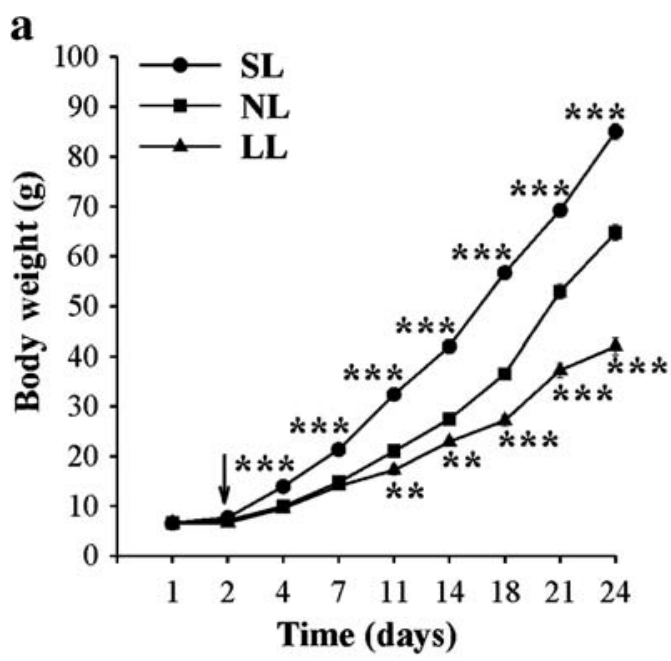

b

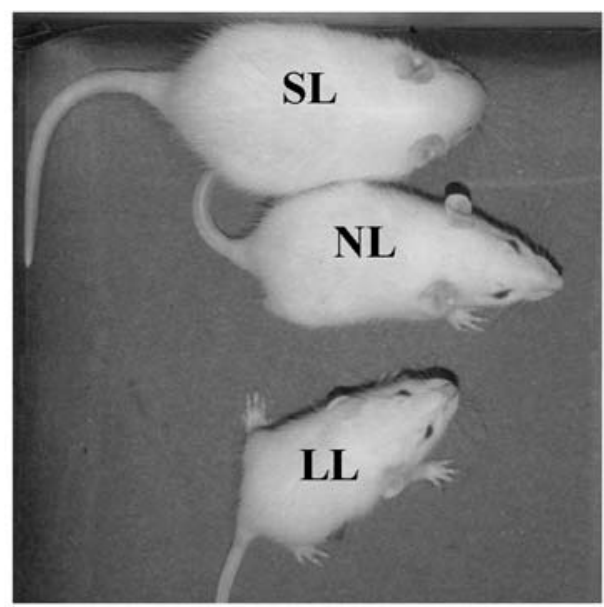


experimental group) the hypothalamus was dissected as previously described $[24,25]$ for RT-PCR study. All these samples were frozen immediately on dry ice and maintained at $-80^{\circ} \mathrm{C}$ until processed. Trunk blood was collected in heparinised tubes, centrifuged immediately and the plasma separated and kept frozen at $-20^{\circ} \mathrm{C}$ until assayed. Due to the presence of circadian changes in hypothalamic mRNA content of the neuropeptides evaluated in this study [2630], the animals (NL, SL and LL) from each experiment (two independent experiments) were killed on the same day (18.00-20.00 hours), just before the dark phase (20.00 hours). In order to completely avoid any possible circadian effect, the animals were killed in an alternate manner, i.e., one rat from each group (NL, SL, LL), rather than all the animals from one experimental group before starting the next group.

Leptin RIA Plasma leptin levels were measured by RIA as previously described [31-33] using reagents provided by commercial kits (Rat leptin RIA, Linco Research, St. Charles, MO, USA). The sensitivity was $0.5 \mathrm{ng} / \mathrm{ml}$, the coefficient of intra-assay and the coefficient of inter-assay variance were $3.3 \%$ and $4.8 \%$ respectively.

Glucose measurements The glucose levels of the animals were determined using a commercial kit based on a colorimetric method (Glucose, Spinreact, Gerona, Spain). Absorbance was measured at $490 \mathrm{~nm}$.

RNA extraction Total RNA from hypothalamus tissue was extracted using Trizol Reagent (Invitrogen, Paisley, UK).

Reverse transcriptase-polymerase chain reaction The RT reaction was carried out in a volume of $30 \mu \mathrm{l}$ containing $1 \mu \mathrm{g}$ of total RNA, and incubated at $37^{\circ} \mathrm{C}$ for $60 \mathrm{~min}$. The enzyme was inactivated by heating at $95^{\circ} \mathrm{C}$ for $5 \mathrm{~min}$. We amplified $3 \mu \mathrm{l}$ of the RT product, using specific sets of primers (Table 1A). The temperature and times used were for OB-R isoforms: 34 cycles at $94^{\circ} \mathrm{C}(1 \mathrm{~min}), 54^{\circ} \mathrm{C}$ (1 $\mathrm{min}), 72^{\circ} \mathrm{C}(1 \mathrm{~min})$; and for hypoxanthine guanine phosphoribosyltransferase (HPRT), which was used as a housekeeping gene: 28 cycles at $94^{\circ} \mathrm{C}(1 \mathrm{~min}), 63^{\circ} \mathrm{C}$ ( $1 \mathrm{~min}), 72^{\circ} \mathrm{C}(1 \mathrm{~min})$. In all cases amplification was carried out with a final extension step at $72^{\circ} \mathrm{C}$ for $10 \mathrm{~min}$. In order to ensure that the PCR reaction was performed within a linear range, samples were amplified for 15, 20, $25,30,35$ and 40 cycles. Kinetics for HPRT and the different isoforms of OB-R have been published elsewhere $[24,31,34]$. The amplified products were resolved in a $2 \%$ agarose gel and quantified by densitometry using a digital imaging system (Molecular Analyst, Biorad, CA, USA) $[24,31,32,34]$. All PCR products were digested with specific restriction enzymes and hybridised with complementary RNA or DNA probes or sequenced in order to determine their specificity $[24,31,34]$. The mRNA content of the different isoforms of OB-R was analysed in each hypothalamus individually.

In situ hybridisation Coronal hypothalamic sections $(16 \mu \mathrm{m})$ were cut on a cryostat, and immediately stored at $-80^{\circ} \mathrm{C}$ until hybridisation. For AgRP, CART, MCH, NPY, prepro$\mathrm{OX}$ and TRH detection we employed the specific antisense oligodeoxynucleotides (Table 1B). These probes were 3'end labelled with ${ }^{35} \mathrm{~S}$-alpha-dATP using terminal deoxynucleotidyl transferase. The specificity of the probes was confirmed by incubating the sections with an excess of the unlabelled probes $[25,33,35,36]$. In situ hybridisations were performed as already reported $[25,32,33,35,36]$. Briefly, the frozen sections were fixed with $4 \%$ paraformaldehyde in $0.1 \mathrm{~mol} / 1$ phosphate buffer (pH 7.4) at room temperature for $30 \mathrm{~min}$. They were then dehydrated using $70 \%, 80 \%, 90 \%, 95 \%$ and absolute ethanol (5 min each). The hybridisation was carried out overnight at $37^{\circ} \mathrm{C}$ in a moist chamber. Hybridisation solution contained $5 \times 10^{5}$ cpm (AgRP, CART, prepro-OX and TRH) or $1 \times 10^{6} \mathrm{cpm}$ (MCH, NPY) per slide of the labelled probe, $4 \times \mathrm{SSC}(20 \times$

Table 1 PCR primers and antisense oligonucleotides for in situ hybridization analysis

\begin{tabular}{|c|c|c|c|}
\hline \multirow[t]{2}{*}{ mRNA } & \multirow[t]{2}{*}{ GenBank accession number } & \multicolumn{2}{|l|}{ Sequence } \\
\hline & & Upper primer & Lower primer \\
\hline \multicolumn{4}{|c|}{ A. PCR primers } \\
\hline OB-Ra & D84125 & 5'-CCTATCGAGAAATATCAGTTTA-3' & 5'-TCAAAGAGTGTCCGCTCTCT-3' \\
\hline $\mathrm{OB}-\mathrm{Rb}$ & D85558 & 5'-CCTGAAACATTTGAGCATCTTT-3' & 5'-CGATGCACTGGCTGACAGAA-3' \\
\hline OB-Rc & AF007818 & 5'-ATTGTACCGGTAATTATTTCCT-3' & 5'-CTGCAACCTTAGATATCTTGG-3' \\
\hline OB-Re & AF007819 & 5'-GCAGAATCAGCACACACTGTT-3' & 5'-GTAAAAGCACAGTACACATACC-3' \\
\hline OB-Rf & U53144 & 5'-AGAGGATATATAGTGGATGCCG-3' & 5'-CACAAATGAGGATCTTCAAACC-3' \\
\hline HPRT & X62085 & 5'-CAGTCCCAGCGTCGTGATTA-3' & 5'-AGCAAGTCTTTCAGTCCTGTC-3' \\
\hline \multicolumn{4}{|c|}{ B. In situ oligos } \\
\hline AgRP & AF206017 & \multicolumn{2}{|c|}{ 5'-CGACGCGGAGAACGAGACTCGCGGTTCTGTGGATCTAGCACCTCTGCC-3' } \\
\hline CART & M29712 & \multicolumn{2}{|c|}{ 5'-CCGAAGGAGGCTGTCACCCCTTCACA-3' } \\
\hline $\mathrm{MCH}$ & M29712 & \multicolumn{2}{|c|}{ 5'-CCAACAGGGTCGGTAGACTCGTCCCAGCAT-3' } \\
\hline NPY & M20373 & \multicolumn{2}{|c|}{ 5'-AGATGAGATGTGGGGGGAAACTAGGAAAAGTCAGGAGAGCAAGTTTCATT-3' } \\
\hline Prepro-OX & AF041241 & \multicolumn{2}{|c|}{ 5'-TTCGTAGAGACGGCAGGAACACGTCTTCTGGCGACA-3' } \\
\hline TRH & M36317 & \multicolumn{2}{|c|}{ 5'-ATACCAGTTAGGGTGAAGATCAAAGCCAGAGCCAGCAGCAACCAA-3' } \\
\hline
\end{tabular}


SSC: $3 \mathrm{~mol} / 1$ sodium chloride, $0.3 \mathrm{~mol} / 1$ sodium citrate, $\mathrm{pH}$ 7), $50 \%$ deionised formamide, $1 \times$ Denhardt's solution, $10 \%$ dextran sulphate and $10 \mu \mathrm{g} / \mathrm{ml}$ sheared, single-stranded salmon sperm DNA (all reagents from Sigma, St Louis, MO, USA). Afterwards, the hybridised sections were sequentially washed in $1 \times \mathrm{SSC}$ at room temperature, four times in $1 \times \mathrm{SSC}$ at $42^{\circ} \mathrm{C}(30$ min per wash), one time in $1 \times$ SSC at room temperature $(1 \mathrm{~h})$, and then rinsed in water and ethanol. Finally, the sections were air-dried and exposed to Hyperfilm $\beta$-Max (Amersham, Buckinghamshire, UK) at room temperature for 4 to 6 days.

To compare anatomically similar regions, the slides were matched according to a rat brain atlas [37]. The slides from control and treated animals, at each treatment time, were always exposed to the same autoradiographic film. For the AgRP and NPY analysis, the ARC was divided from rostral to caudal into four subdivisions based on three previous studies [38-40], using the brain atlas [37]. In our study the anterior (rostral) ARC corresponded from the beginning of the dorsomedial nucleus (DMN) (coronal plate 20 of the rat brain atlas) to the compact zone of the DMN (coronal plate 21 of the rat brain atlas). The posterior (caudal) part of the ARC began with the disappearance of the DMN to the end of the ARC (coronal plate 22 of the rat brain atlas). The coronal brain sections were anatomically matched across animals from all the three groups. Due to AgRP and NPY coexpression in the same cells [3, 4, 40, 41] the study was performed in serial sections of each brain.

All sections were scanned and the specific hybridisation signal was quantified by densitometry using a digital imaging system (Molecular Analyst, Biorad) [24, 25, 3236]. The optical density of the hybridisation signal was determined and subsequently corrected by the optical density of its adjacent background value. For this reason, a rectangle, with the same dimensions in each case, was drawn enclosing the hybridisation signal over each nucleus and over adjacent brain areas of each section (background). We used 16 to 20 sections for each animal (four to five slides, four sections per slide). The mean of these 16 to 20 values was used as the densitometry value for each animal. The coefficients of intra-assay variance were $5.8 \%$ for AgRP, $6.6 \%$ for CART, $6.3 \%$ for $\mathrm{MCH}, 6.9 \%$ for NPY, $5.4 \%$ for prepro-OX and $6.4 \%$ for TRH. The coefficients of interassay variance were $8.3 \%$ for AgRP, $8.4 \%$ for CART, $5.2 \%$ for $\mathrm{MCH}, 7.6 \%$ for NPY, $10.9 \%$ for preproOX and $9.5 \%$ for TRH.

Statistical analysis and data presentation Data were expressed as means \pm SEM and analysed using a computerised package for statistical analysis (GraphPad InStat 2.0.4, GraphPad Software, CA, USA). Statistically significant difference was determined by ANOVA followed by a post hoc multiple comparisons Bonferroni test. A $p$ value of $<0.05$ was considered to be significant. Data of mRNA levels were presented as percentage change in relation to control values.

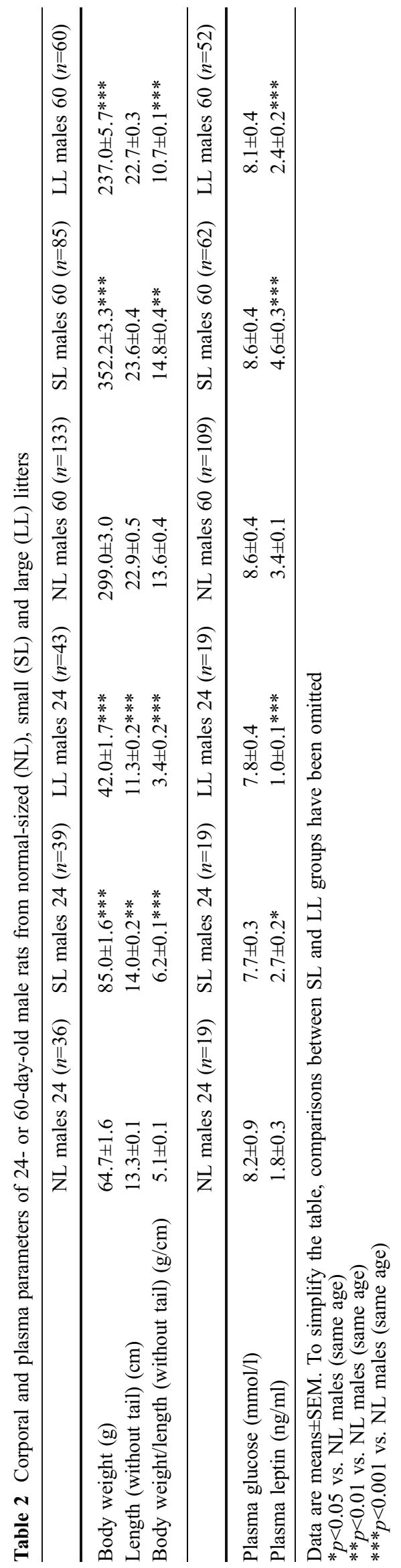




\section{Results}

Effects of neonatal feeding on body weight, body size and relative body weight As shown in Fig. 1a and in Table 2, SL males showed a significant increase in body weight gain during the suckling period until weaning. This increase in body weight was accompanied by an increment in body length (excluding tail: nasal-anal distance). However, there was a significant increase in the relative body weight (body weight/body length) of these animals when compared with the other experimental groups, indicating a state of obesity [22]. On the other hand, underfed 24-day-old LL males showed a significantly lower body weight, body length (excluding tail: nasal-anal distance) and relative body weight when compared with NL rats. The anatomical differences in 24-day-old male rats are illustrated in Fig. 1b. These differences in body weight were maintained in 60-day-old rats (Table 2). At 90 days of age the body weight patterns were maintained (data not shown).

Effects of neonatal feeding on serum glucose and serum leptin levels Plasma glucose levels did not differ significantly among groups (Table 2). Leptin levels were altered, SL male rats were significantly hyperleptinaemic $(p<0.05)$, whereas the LL group was markedly hypoleptinaemic $(p<0.01)$. These differences were maintained at 60 days of age (Table 2).

Effects of neonatal feeding on hypothalamic mRNA content of $O B-R s$ Using RT-PCR analysis we detected a significant and selective decrease in the mRNA content of the long isoform of the leptin receptor (OB-Rb) in the hypothalamus of 24-day-old SL male rats. No changes were found in the short isoforms. In contrast, in 24-dayold LL male rats we found a significant increase in the hypothalamic mRNA content of the short OB-Rc and OBRf isoforms (Fig. 2).

Fig. 2 a Representative RTPCR assay of OB-Ra, OB-Rb, OB-Rc, OB-Re and OB-Rf mRNA expression in the hypothalamus of 24-day-old male rats from normal-sized litters $(N L)$, small litters $(S L)$ and large litters $(L L)$. Amplification of endogenous HPRT mRNA was considered as control. b OB-Rs mRNA levels in the hypothalamus of the described groups. The results were corrected by HPRT mRNA levels. $* * p<0.01$ vs. NL; ${ }^{\#} p<0.05$ SL vs. LL; ${ }^{\#} p<0.01$ SL vs. LL a

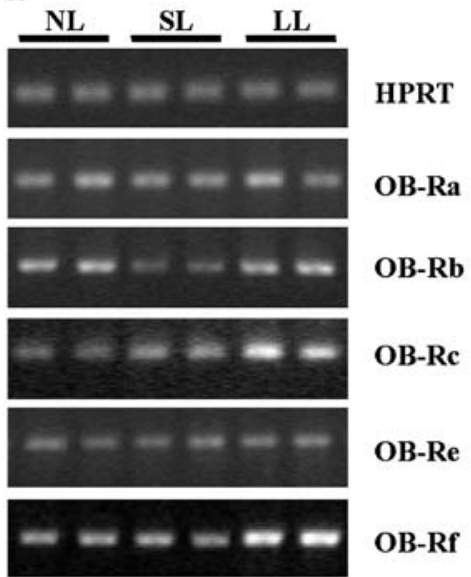

Effects of neonatal feeding on hypothalamic mRNA content of orexigenic and anorexigenic neuropeptides We demonstrated an increase in the mRNA levels of hypothalamic AgRP and NPY in SL male rats. Interestingly, these changes were specifically located in the posterior (caudal) part of the ARC, without any change in the anterior (rostral) ARC. We were unable to demonstrate any change in the mRNA content of any of the other orexigenic neuropeptides evaluated in this study (NPY in $\mathrm{DMN}, \mathrm{MCH}$ in LHA, and prepro-OX in LHA) in this group of obese young rats (Fig. 3). Of the anorexigenic neuropeptides studied, we were able to detect a significant increase of CART mRNA content in the ARC, without any change in other nuclei expressing CART, such as the PVN and LHA (Fig. 3). Pro-TRH mRNA levels were unchanged in these rats (Fig. 3).

Large-litter rats showed a large increment of the mRNA levels of AgRP and NPY in the ARC (both rostral and caudal parts), while no changes were observed in the DMN. Moreover, we were unable to find changes in $\mathrm{MCH}$ and prepro-OX mRNA levels in the LHA, CART mRNA levels in all nuclei studied (in the ARC, PVN and LHA) and pro-TRH mRNA content in the PVN (Fig. 3).

\section{Discussion}

One classical model to study the effect of early overfeeding and underfeeding is the manipulation of the size of the rat litters in the first days of postnatal life [10, 22, 4244]. Our data show that rats growing up in SLs gain more weight than rats growing up in NLs; moreover, as has been previously demonstrated, this phenotype is maintained in adulthood. On the other hand, rats raised in LLs show a delay in growth and a decrease in body weight. Although in this latter model the normal phenotype is recovered in adults [22], our LL rats did not recover the normal values. The reason for this discrepancy with the previous data is not clear; it could be related to the different genetic

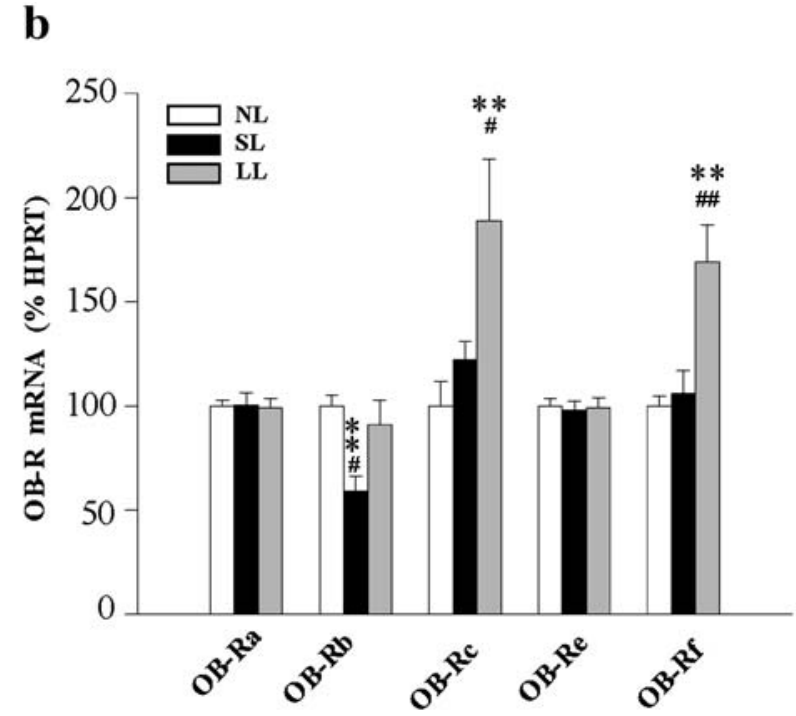


a

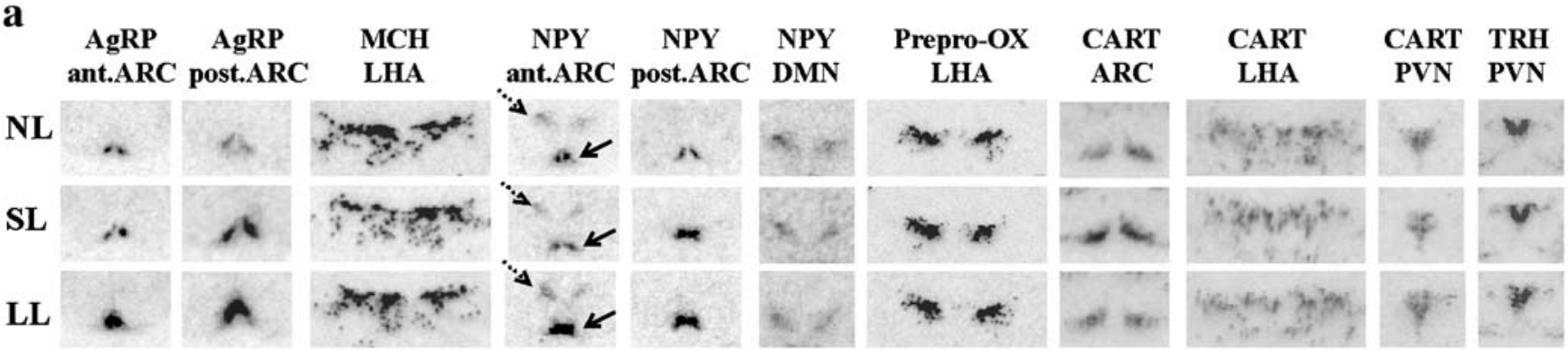

b

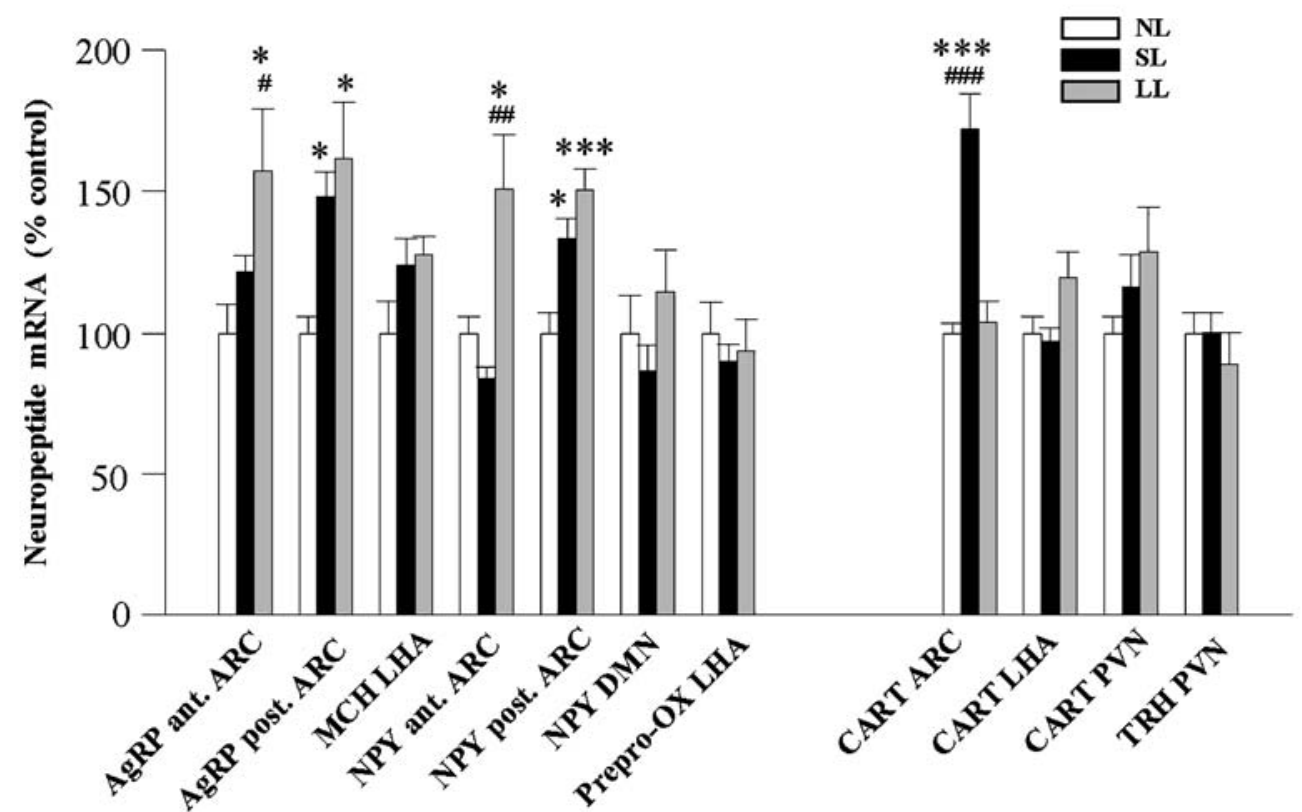

Fig. 3 a Representative autoradiographic images of representative brain coronal sections, incubated with ${ }^{35} \mathrm{~S}$-labelled antisense oligonucleotide probes, for the named neuropeptides, in 24-day-old male rats from normal-sized litters $(N L)$, small litters $(S L)$ and large litters $(L L)$. In the NPY ant. ARC column, the solid arrows show NPY in

background of the animals used in both studies: Wistar rats in the previous paper [22] and Sprague-Dawley in our study. Another possibility could be that in the previous report the weaning was set at 21 days [22] and we selected day 24 for the complete weaning of the LL pumps.

Alterations in the litter size of rats induce overfeeding, which leads to obese animals, or underfeeding which leads to lean phenotypes. This effect could be explained in terms of milk intake $[10,45]$. The key aspect of the overfed model is that these rats maintain the obese phenotype throughout their lives $[19,22,44]$. These data suggest that perinatal feeding is a crucial factor in the development of obesity [22, 46, 47]. Thus, unravelling the hypothalamic mechanisms involved in feeding in these two experimental models (overfed and underfed neonatal rats) could help us to understand the influence that perinatal food intake has on the establishment of these central mechanisms, as well as on the development of these phenotypes.

In our study, early postnatal overfeeding (SL) induces a marked increment in the body weight of the rats. Their increase in body weight was accompanied by an increase in the ARC and dotted arrows show NPY in the DMN. b Neuropeptide mRNA levels in the different hypothalamic nuclei of the described experimental groups. ${ }^{*} p<0.05$ vs. $\mathrm{NL} ;{ }^{* * *} p<0.001$ vs. NL; ${ }^{*} p<0.05$ SL vs. LL; ${ }^{\prime} p<0.01$ SL vs. LL; ${ }^{\# \#} p<0.001$ SL vs. LL

body length. Even with this increased body length, their relative body weight (body weight/body length) was significantly higher than the relative body weight of rats with normal feeding (NL), indicating an obese phenotype $[10,19]$. This is further demonstrated by the high leptin levels observed in these rats, indicating a large amount of adipose tissue [5, 48]. On the other hand, underfed rats (LL) were, as expected, underweight and had an important decrease in both body length and relative body weight probably due to lower caloric intake $[19,44]$. The reduction in the amount of adipose tissue induced an important decrease in plasma leptin levels. Very interestingly, all these changes were maintained at 60 days of age.

The hyperleptinaemia exhibited by the obese SL rats suggested that a state of leptin resistance might exist at the hypothalamic level [15-18], explaining the hyperphagia observed in this model $[22,45,49]$. In order to study this issue further, mRNA levels encoding the different leptin receptor isoforms were determined in the hypothalamus of NL, SL and LL rats. Interestingly, we found a specific decrease of the mRNA levels encoding the leptin receptor 
long isoform (OB-Rb) in the hypothalamus of SL rats compared to the NL group. This result suggests that a decrease in the expression of the long, biologically active form of the leptin receptor in the hypothalamus of the SL rats might explain, at least in part, a physiological resistance of these obese rats to the high levels of serum leptin. Leptin resistance based on a specific decrease in the $\mathrm{OB}-\mathrm{Rb}$ in the hypothalamus has already been described during gestation in rats $[31,50]$ (another hyperleptinaemic and hyperphagic state) and is the major feature of obesity in the $d b / d b$ model $[5,48]$. Additionally, data obtained in humans have shown that high leptin concentrations (associated with greater body adiposity) during early postnatal life program a leptin-dependent feedback loop such that regulation of body fat is less sensitive to leptin in later life [14]. Our data suggest that the mechanisms involved in the effects of early feeding on leptin sensitivity could be mediated by changes in the expression of the different isoforms of leptin receptors. Of course, we cannot exclude that other possible mechanisms of leptin resistance, such as the saturation of the leptin transport across the blood-brain barrier $[51,52]$, are present in the SL model. Further work will be needed to test this issue.

Regarding the lean LL rats, hypothalamic OB-Rb mRNA content was similar to that observed in NL rats, but we found an increased expression of two of the short forms of the leptin receptor, OB-Rc and OB-Rf. The function of these short isoforms is not very well established, but it has been proposed that they can act as leptin sequesters, because they bind leptin with high affinity but do not transduce signalling [4, 5]. Thus, our data might reflect a decrease in leptin signalling in the hypothalamus of these lean and food-restricted animals. Furthermore, this might amplify the effects induced by the low levels of leptin on feeding, including a further increase in orexigenic pathways. A similar mechanism has already been described in other hyperphagic states, such as lactation in rats [31].

Numerous hypothalamic neuropeptides have been identified as possible regulators of food intake and metabolism [3, 4, 21, 53]. In order to unravel the feeding mechanisms involved in the development of the obese phenotype induced by neonatal overfeeding, we evaluated the mRNA levels of several hypothalamic orexigenic and anorexigenic neuropeptides, including AgRP, MCH, NPY and prepro-OX, (orexigenic), and CART and TRH (anorexigenic). NPY is a potent orexigenic peptide. For this action, it is mainly produced in the neurons located in the medial part of the arcuate hypothalamic nucleus, and the nerve fibres from this nucleus project into various hypothalamic sites that are implicated in the regulation of feeding behaviour, in particular the paraventricular nucleus (PVN) [3, 4, 53].

AgRP is the most potent orexigenic peptide described so far. It is synthesised in the ARC, in neurons which coexpress both AgRP and NPY [3, 4, 40, 41]. Our data demonstrated a marked increase in the mRNA content of NPY and AgRP in the ARC nucleus of the obese SL rats. Very interestingly, this increase was restricted to the posterior (caudal) part of the nucleus, with no change in the anterior or medial part of the nucleus. This regional upregulation of AgRP and NPY mRNA levels in the caudal ARC has already been reported in another hyperphagic model, the lactating rat $[39,40]$. These data together with our results suggest the existence of different populations of AgRP/NPY-synthesising neurons in the ARC. Moreover, this evidence indicates that these populations play different roles. On the other hand, our data indicate that caudal NPY- and AgRP-expressing neurons might be responsible, at least in part, for the obese phenotype of the SL rats. Taking into account the high serum leptin levels observed in the obese SL rats, the increase in NPY and AgRP expression in the ARC is somewhat surprising, as both neuropeptides are direct targets of leptin-inhibiting actions in the hypothalamus [3, 4]. However, the downregulation of the hypothalamic expression of $\mathrm{OB}-\mathrm{Rb}$ exhibited by this group of animals might suggest this leptin resistance. Further studies using in situ hybridisation will be needed to prove whether the down-regulation of $\mathrm{OB}-\mathrm{Rb}$ occurs specifically in the caudal part of the ARC.

Regarding the other orexigenic neuropeptides evaluated, there was no significant change in the expression of $\mathrm{MCH}$ and prepro-OX in the LHA in SL rats. These results suggest that $\mathrm{MCH}$ and the orexins are not likely to be implicated in the increase in food intake observed in these animals. Among the anorexigenic signals studied here, we only found an increase in the mRNA content of CART in the ARC, with no changes in the PVN or LH. CART mRNA expression in the ARC is stimulated by leptin $[3,4$, $53,54]$ and SL rats are hyperleptinaemic. In this case, our result could suggest that $\mathrm{OB}-\mathrm{Rb}$ is regulated in a neuronal specific form in the ARC of obese animals, and that the described down-regulation shown in this work occurs specifically in the medial part of the caudal ARC where AgRP/NPY neurons are located [55], but it does not occur in the lateral ARC, where CART neurons are located. This nuclei-specific pattern of regulation of CART expression has been previously described in other feeding disorders, such as those caused by alterations in thyroid status [32] and indicates different roles for these neuronal populations.

Finally, in the hypothalamus of LL rats we detected an increase in the mRNA levels of AgRP and NPY in the ARC (both rostral and caudal parts) that could increase the orexigenic signal in these underfed animals. This upregulation could be explained in terms of low leptin signalling, based on hypoleptinaemia combined with upregulation of the short isoforms of the leptin receptor. On the other hand, these data confirm and extend previous observations showing up-regulation of NPY protein concentration and immunoreactivity in this model [19] and the up-regulation of NPY mRNA levels in other neonatally undernourished rats [56]. In contrast, NPY in the DMN, $\mathrm{MCH}$ and prepro-OX mRNA levels in the LHA were not altered, suggesting that the different orexigenic signals play different roles in this underfed model. Moreover, the lack of change of orexin mRNA in these animals could be related to previous studies that demonstrate that prepro-OX expression is only regulated by leptin in fasting conditions 
[24]. No change was observed in the mRNA levels of the anorexigenic signals evaluated in this study, i.e., CART and TRH, in LL rats.

In summary, in this paper we demonstrate that perinatal feeding induces remarkable responses in leptin receptors and neuropeptides in the hypothalamus. We found that early feeding before weaning leads to changes in the expression of the different leptin receptor isoforms. In addition, our data showing that alterations acquired during early development of the function of hypothalamic regulatory centres, namely AgRP/NPY and CART neurons, could play a role in the development of disturbances in body weight homeostasis in adulthood. In particular, our data about rats overfed in the early postnatal state show a leptin-resistant state mediated by down-regulation of the $\mathrm{OB}-\mathrm{Rb}$ isoform, together with increased expression of NPY and AgRP in specific neurons in the ARC, indicating the existence of disturbed hormone-dependent organisation in this nucleus. This may provide a new aetiopathogenic concept for susceptibility to obesity.

Acknowledgements We would like to thank Luz Casas for her excellent technical assistance. This work was supported by grants from Fondo de Investigaciones Sanitarias, Spanish Ministry of Health, Xunta de Galicia, DGICYT and European Union (LSHMCT-2003-503041).

\section{References}

1. Saper CB, Chou TC, Elmquist JK (2002) The need to feed: homeostatic and hedonic control of eating. Neuron 36:199-211

2. Flier JS (2004) Obesity wars: molecular progress confronts an expanding epidemic. Cell 116:337-350

3. Kalra SP, Dube MG, Pu S, Xu B, Horvath TL, Kalra PS (1999) Interacting appetite-regulating pathways in the hypothalamic regulation of body weight. Endocr Rev 20:68-100

4. Meister B (2000) Control of food intake via leptin receptors in the hypothalamus. Vitam Horm 59:265-304

5. Ahima RS, Flier JS (2000) Leptin. Annu Rev Physiol 62:413437

6. Friedman JM, Halaas JL (1998) Leptin and the regulation of body weight in mammals. Nature 395:763-770

7. Hebebrand J, Sommerlad C, Geller F, Gorg T, Hinney A (2001) The genetics of obesity: practical implications. Int J Obes Relat Metab Disord 25(Suppl 1):S10-S18

8. O'Rahilly S, Farooqi IS, Yeo GS, Challis BG (2003) Minireview: human obesity-lessons from monogenic disorders. Endocrinology 144:3757-3764

9. Schwartz MW, Woods SC, Seeley RJ, Barsh GS, Baskin DG, Leibel RL (2003) Is the energy homeostasis system inherently biased toward weight gain? Diabetes 52:232-238

10. Lucas A (1998) Programming by early nutrition: an experimental approach. J Nutr 128:401S-406S

11. Harder T, Kohlhoff R, Dorner G, Rohde W, Plagemann A (2001) Perinatal 'programming' of insulin resistance in childhood: critical impact of neonatal insulin and low birth weight in a risk population. Diabet Med 18:634-639

12. Plagemann A, Harder T, Rake A, Melchior K, Rohde W, Dorner G (2000) Hypothalamic nuclei are malformed in weanling offspring of low protein malnourished rat dams. J Nutr 130:2582-2589

13. Davidowa H, Li Y, Plagemann A (2003) Altered responses to orexigenic (AGRP, MCH) and anorexigenic (alpha-MSH, CART) neuropeptides of paraventricular hypothalamic neurons in early postnatally overfed rats. Eur J Neurosci 18:613-621
14. Singhal A, Farooqi IS, O'Rahilly S, Cole TJ, Fewtrell M, Lucas A (2002) Early nutrition and leptin concentrations in later life. Am J Clin Nutr 75:993-999

15. Schmidt I, Schoelch C, Ziska T, Schneider D, Simon E, Plagemann A (2000) Interaction of genetic and environmental programming of the leptin system and of obesity disposition. Physiol Genomics 3:113-120

16. Davidowa H, Plagemann A (2000) Decreased inhibition by leptin of hypothalamic arcuate neurons in neonatally overfed young rats. NeuroReport 11:2795-2798

17. Davidowa H, Plagemann A (2000) Different responses of ventromedial hypothalamic neurons to leptin in normal and early postnatal overfed rats. Neurosci Lett 293:21-24

18. Schmidt I, Fritz A, Scholch C, Schneider D, Simon E, Plagemann A (2001) The effect of leptin treatment on the development of obesity in overfed suckling Wistar rats. Int J Obes Relat Metab Disord 8:1168-1174

19. Plagemann A, Harder T, Rake A et al (1999) Observations on the orexigenic hypothalamic neuropeptide Y-system in neonatally overfed weanling rats. J Neuroendocrinol 11:541-546

20. Davidowa H, Plagemann A (2001) Inhibition by insulin of hypothalamic VMH neurons in rats overweight due to postnatal overfeeding. NeuroReport 12:3201-3204

21. Jeanrenaud B, Rohner-Jeanrenaud F (2001) Effects of neuropeptides and leptin on nutrient partitioning: dysregulations in obesity. Annu Rev Med 52:339-351

22. Plagemann A, Heidrich I, Gotz F, Rohde W, Dorner G (1992) Obesity and enhanced diabetes and cardiovascular risk in adult rats due to early postnatal overfeeding. Exp Clin Endocrinol 99:154-158

23. Hall WG (1985) What we know and don't know about the development of independent ingestion in rats. Appetite 6:333356

24. López M, Seoane L, García MC et al (2000) Leptin regulation of prepro-orexin and orexin receptor mRNA levels in the hypothalamus. Biochem Biophys Res Commun 269:41-45

25. López M, Seoane LM, García MC, Diéguez C, Señarís R (2002) Neuropeptide Y, but not agouti-related peptide or melanin-concentrating hormone, is a target peptide for orexin-a feeding actions in the rat hypothalamus. Neuroendocrinology 75:34-44

26. Zoeller RT, Kabeer N, Albers HE (1990) Cold exposure elevates cellular levels of messenger ribonucleic acid encoding thyrotropin-releasing hormone in paraventricular nucleus despite elevated levels of thyroid hormones. Endocrinology 127:2955-2962

27. Akabayashi A, Levin N, Paez X, Alexander JT, Leibowitz SF (1994) Hypothalamic neuropeptide Y and its gene expression: relation to light/dark cycle and circulating corticosterone. Mol Cell Neurosci 5:210-218

28. Bluet-Pajot MT, Presse F, Voko Z et al (1995) Neuropeptide-E-I antagonizes the action of melanin-concentrating hormone on stress-induced release of adrenocorticotropin in the rat. J Neuroendocrinol 7:297-303

29. Taheri S, Sunter D, Dakin C et al (2000) Diurnal variation in orexin A immunoreactivity and prepro-orexin mRNA in the rat central nervous system. Neurosci Lett 279:109-112

30. Angel VM, Uribe RM, Cisneros M et al (2002) Thyrotropinreleasing hormone regulates the diurnal variation of pyroglutamyl aminopeptidase II activity in the male rat adenohypophysis. Eur J Endocrinol 147:363-369

31. García MC, Casanueva FF, Diéguez C, Señarís R (2000) Gestational profile of leptin messenger ribonucleic acid (mRNA) content in the placenta and adipose tissue in the rat, and regulation of the mRNA levels of the leptin receptor subtypes in the hypothalamus during pregnancy and lactation. Biol Reprod 62:698-703

32. López M, Seoane LM, Tovar S, Señarís R, Diéguez C (2002) Thyroid status regulates cocaine and amphetamine-regulated transcript but not agouti-related peptide mRNA levels in the rat hypothalamus. NeuroReport 13:1775-1779 
33. García MC, López M, Gualillo O, Seoane L, Diéguez C, Señarís R (2003) Hypothalamic levels of NPY, MCH, and prepro-orexin mRNA during pregnancy and lactation in the rat: role of prolactin. FASEB J 17:1392-1400

34. López M, Seoane L, Señarís R, Diéguez C (2001) Preproorexin mRNA levels in the rat hypothalamus, and orexin receptors mRNA levels in the rat hypothalamus and adrenal gland are not influenced by the thyroid status. Neurosci Lett 300:171-175

35. Seoane LM, López M, Tovar S, Casanueva F, Señarís R, Diéguez C (2003) Agouti-related peptide, neuropeptide Y, and somatostatin-producing neurons are targets for ghrelin actions in the rat hypothalamus. Endocrinology 144:544-551

36. López M, Seoane LM, Tovar S, Nogueiras R, Diéguez C, Señarís R (2004) Orexin-A regulates growth hormone releasing hormone mRNA content in a nucleus specific manner and somatostatin mRNA content in a growth hormone-dependent fashion in the rat hypothalamus. Eur J Neurosci 19:2080-2088

37. Paxinos G, Watson C (1986) The rat brain in stereotaxic coordinates. Academic, Sydney

38. Smith MS (1993) Lactation alters neuropeptide-Y and proopiomelanocortin gene expression in the arcuate nucleus of the rat. Endocrinology 133:1258-1265

39. Li C, Chen P, Smith MS (1998) The acute suckling stimulus induces expression of neuropeptide Y (NPY) in cells in the dorsomedial hypothalamus and increases NPY expression in the arcuate nucleus. Endocrinology 139:1645-1652

40. Chen P, Li C, Haskell-Luevano C, Cone RD, Smith MS (1999) Altered expression of agouti-related protein and its colocalization with neuropeptide $\mathrm{Y}$ in the arcuate nucleus of the hypothalamus during lactation. Endocrinology 140:2645-2650

41. Hahn TM, Breininger JF, Baskin DG, Schwartz MW (1998) Coexpression of AgRP and NPY in fasting-activated hypothalamic neurons. Nat Neurosci 1:271-272

42. McCance RB (1962) Food, growth, and time. Lancet 2:671676

43. Oscai LB, McGarr JA (1978) Evidence that the amount of food consumed in early life fixes appetite in the rat. Am J Physiol 235:R141-R144

44. Heidel E, Plagemann A, Davidowa H (1999) Increased response to NPY of hypothalamic VMN neurons in postnatally overfed juvenile rats. NeuroReport 10:1827-1831
45. Babicky A, Ostadalova I, Parizek J, Kolar J, Bibr B (1973) Onset and duration of the physiological weaning period for infant rats reared in nests of different sizes. Physiol Bohemoslov 22:449-456

46. Dorner G, Mohnike A, Honigmann G, Singer P, Padelt H (1973) Possible significance of prenatal hyperinsulinism for postnatal development of diabetes mellitus. Endokrinologie $61: 430-432$

47. Vannier C, Gaillard D, Grimaldi P et al (1985) Adipose conversion of ob17 cells and hormone-related events. Int J Obes 9(Suppl 1):41-53

48. Casanueva FF, Dieguez C (1999) Neuroendocrine regulation and actions of leptin. Front Neuroendocrinol 20:317-363

49. Plagemann A, Harder T, Rake A et al (1999) Perinatal elevation of hypothalamic insulin, acquired malformation of hypothalamic galaninergic neurons, and syndrome $x$-like alterations in adulthood of neonatally overfed rats. Brain Res 836:146-155

50. Seeber RM, Smith JT, Waddell BJ (2002) Plasma leptinbinding activity and hypothalamic leptin receptor expression during pregnancy and lactation in the rat. Biol Reprod $66: 1762-1767$

51. Burguera B, Couce ME, Curran GL et al (2000) Obesity is associated with a decreased leptin transport across the bloodbrain barrier in rats. Diabetes 49:1219-1223

52. Furuhata Y, Kagaya R, Hirabayashi K et al (2000) Development of obesity in transgenic rats with low circulating growth hormone levels: involvement of leptin resistance. Eur J Endocrinol 143:535-541

53. Schwartz MW, Woods SC, Porte D Jr, Seeley RJ, Baskin DG (2000) Central nervous system control of food intake. Nature 404:661-671

54. Williams G, Harrold JA, Cutler DJ (2000) The hypothalamus and the regulation of energy homeostasis: lifting the lid on a black box. Proc Nutr Soc 59:385-396

55. Mercer JG, Hoggard N, Williams LM et al (1996) Coexpression of leptin receptor and preproneuropeptide Y mRNA in arcuate nucleus of mouse hypothalamus. J Neuroendocrinol 8:733-735

56. Kowalski TJ, Houpt TA, Jahng JW, Okada K, Chua SC, Smith GP (1998) Ontogeny of neuropeptide Y expression in response to deprivation in lean Zucker rat pups. Am J Physiol 44:R466R470 